Final technical report: Production Mechanism, Number Concentration, Size Distribution, Chemical Composition, and Optical Properties of Sea Spray Aerosols

Production Mechanism, Number Concentration, Size Distribution, Chemical Composition, and Optical Properties of Sea Spray Aerosols

Final Project Report for the period 06/01/2012 - 05/31/2013

U.S. Department of Energy, Grant No: DOE-DE-SC0007995

Principal investigator: Nicholas Meskhidze

Associate Professor

Marine Earth and Atmospheric Sciences

North Carolina State University

Tel: (919) 515-7243

Co-PIs: Markus Petters, Kostas Tsigaridis 
Final technical report: Production Mechanism, Number Concentration, Size Distribution, Chemical Composition, and Optical Properties of Sea Spray Aerosols

\section{Major Activities:}

What: About forty scientists from six countries convened on a 3-day workshop to review the status and prospects of sea spray aerosol research. Participants were researchers from both the oceanography and atmospheric science communities, including academia, private industry, and government agencies. A list of workshop presentations is available online (http://www4.ncsu.edu/ nmeskhi/Marine_Aerosol_Workshop/WEBSITE.html).

When: 4-6 June 2012

Where: Raleigh, NC, USA

\section{Specific Objectives:}

The objective of this workshop was to address the most urgent open science questions for improved quantification of sea spray aerosol-radiation-climate interactions. Sea spray emission and its influence on global climate remains one of the most uncertain components of the aerosol-radiation-climate problem, but has received less attention than other aerosol processes (e.g. production of terrestrial secondary organic aerosols). Thus, the special emphasis was placed on the production flux of sea spray aerosol particles, their number concentration and chemical composition and properties.

\section{Significant Results:}

Improving the understanding of sea spray aerosols requires additional laboratory studies, field measurements, remote sensing, and modeling research. Several specific ideas were suggested during the course of the meeting, including:

1) Tabulation of a set of terminology involving sea spray aerosols that is consistent among oceanographers, atmospheric scientists, and computer modelers.

2) Standardization of artificial sea water and laboratory intercalibration of sea spray production sources using the same artificial and natural seawater. Several participants felt that a center focused on sea spray aerosols would help ensure standardization.

3) Standard oceanic, aerosol, and meteorological measurements that should be included, if possible, in all field campaigns focusing on sea spray aerosol. As a starting point the group suggested a list presented above in the "in-situ field measurements" section.

4) A model intercomparison of the bulk and size-resolved number concentration and chemical composition of marine aerosols, preferably in the framework of AeroCom.

5) Creation of a size-resolved sea spray aerosol observational database that includes chemical composition, biological composition, and number concentration.

6) Identifying locations for studies where instrumentation, model results, and remote sensing products could be effectively brought together in a suitable and predictable environment. 
Final technical report: Production Mechanism, Number Concentration, Size Distribution, Chemical Composition, and Optical Properties of Sea Spray Aerosols

Ultimately, the participants of this meeting stressed the need for better communication between interdisciplinary fields of sea spray aerosol research. Collaboration between those doing laboratory studies, field measurements, remote sensing, and modeling efforts was stated as being essential in order to quickly improve the understanding of the complex issues involving sea spray aerosols.

\section{Key outcomes or Other achievements:}

Instead of relying on individual presentations, the meeting format was structured to emphasize consensus-building among participants who collectively discussed successes, weaknesses, and research goals and methods of achieving them in their specific expertise of sea spray aerosol research. Following a keynote presentation by Gerrit de Leeuw highlighting open questions from his perspective, the workshop participants were divided into four focus groups: in-situ field measurements, laboratory experiments, remote sensing, and regional and global modeling. Following short presentations by the group leaders in which successes and difficulties of past measurements/modeling/remote sensing efforts were reviewed and important missing parameters were identified, participants deliberated in breakout sessions to discuss three major topics: sea spray source function, atmospheric aging and budget, and optical properties. In each session, participants elaborated on the current sea spray aerosolrelated research status and identified future priorities.

Contributions for the workshop were also provided by NSF, NASA, NOAA and ONR. Fig. 1 shows a description of a method of consensus building during the workshop sessions. The presentations are available at www4.ncsu.edu/ nmeskhi/Marine_Aerosol_Workshop/WEBSITE.html.

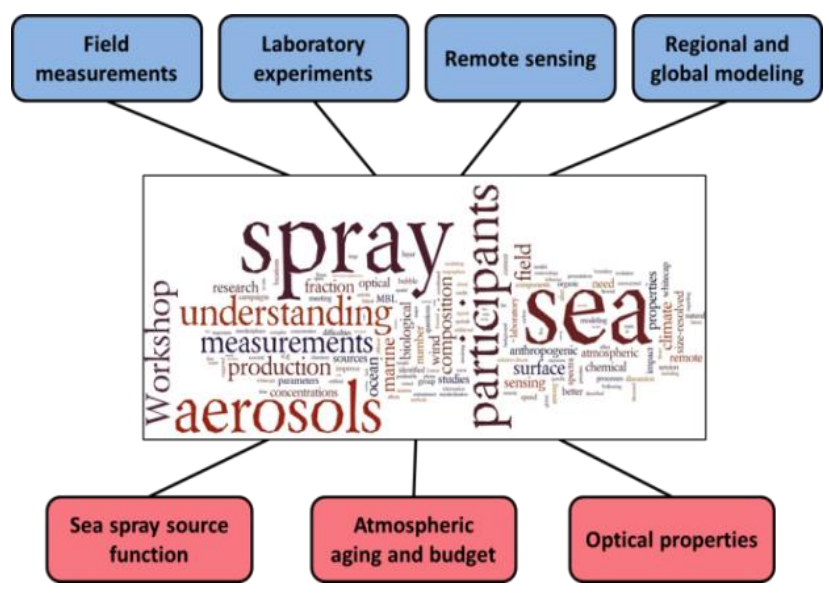

Figure 1. The four main focus groups followed by the three breakout sessions used for the discussion related to current sea spray aerosol-related research status and future priorities. The word cloud was generated through the Wordle software (http://www.wordle.net/) using the workshop discussions. The more frequently a word is used in the text, the larger that word appears in the word cloud. 
Final technical report: Production Mechanism, Number Concentration, Size Distribution, Chemical Composition, and Optical Properties of Sea Spray Aerosols

\section{Peer-reviewed publications resulted from DOE-DE-SC0007995 project:}

1. Meskhidze, N., M. D. Petters, K. Tsigaridis, T. Bates, C. O'Dowd, J. Reid, E. R. Lewis, B. Gantt, M. D. Anguelova, P. V. Bhave, J. Bird, A. H. Callaghan, D. Ceburnis, R. Chang, A. Clarke, G. de Leeuw, G. Deane, P. J. DeMott, S. Elliot, M. C. Facchini, C. W. Fairall, L. Hawkins, Y. Hu, J. G. Hudson, M. S. Johnson, K. C. Kaku, W. C. Keene, D. J. Kieber, M. S. Long, M. Martensson, R. L. Modini, C. L. Osburn, K. A. Prather, A. Pszenny, M. Rinaldi, L. M. Russell, M. Salter, A. M. Sayer, A. Smirnov, S. R. Suda, T. D. Toth, D. R. Worsnop, A. Wozniak, and S. R. Zorn (2013), Production mechanisms, number concentration, size distribution, chemical composition, and optical properties of sea spray aerosols, Atmos Sci Lett, DOI: $10.1002 /$ asl2.441. 